\title{
A Framework for Business IT Alignment in Turbulent Environments
}

\author{
By Fabrizio Amarilli*
}

The paper proposes a framework for organizations' business IT alignment that merges traditional IT assessment parameters, such as application portfolio coverage and integration, with technological and architectural parameters providing flexibility to the company's Information System. The framework proves to be a practical decisional instrument, overcoming theoretical approaches which lack applicability to decision processes, especially in turbulent environments, where business needs may vary quickly and the adaptation capability of the Information System is a key competitive factor.

\section{Introduction}

Business IT alignment has been widely analysed by researchers and practitioners over the last 20 years and a number of studies have been published. Despite the richness in literature, following are some of the reasons why this topic still deserves attention:

(i) Despite the apparent importance of aligning business and IT, the majority of the publications remain rather vague in terms of how to define and measure the alignment (Maes et al., 2000).

(ii) With the exception of few studies, most analyses focus on the alignment from a strategic perspective, addressing the process of guaranteeing business strategy and IT strategy, matching, but lacking, instruments and practical approaches to implement the alignment in companies (Cataldo et al., 2012; Chan and Reich, 2007; Cragg and Tagliavini, 2006).

(iii) Despite addressing turbulence and flexibility, researches mostly analyse the relationship between the flexibility of Information Systems and the company's performances, in order to prove the positive correlation (Power and Reid, 2005; Taskin and Verville, 2010), but they do not embed flexibility, as a design parameter, into the alignment models.

This paper gives a contribution, to the field of research, through the proposal of a new framework which can be adopted by organizations to better

*Lecturer, Fondazione Politecnico di Milano, Italy. 
assist the achievement of business objectives and design ICT support to business processes, taking into account the turbulence of current competitive environments and the consequent need of flexibility.

The paper is organized as follows: the following section presents a review of alignment models existing in literature in order to highlight the importance of focusing on the alignment's process perspective ; then a new framework for alignment, based on the process perspective, is proposed and discussed; some lessons derived from the application of the framework to assess the alignment of a set of companies in Italy is commented and the application of the framework to support the choice of the target Information System configuration for a manufacturing SME operating in Italy is discussed in detail.

\section{Literature Review on Business IT Alignment}

The complexity of the business IT alignment problem is reflected in the abundance of literature. Over the years several models have been proposed, addressing specific aspects of the alignment. The models can therefore be analyzed and classified according to different perspectives (Orlikowski, 1996).

Cataldo et al. (Cataldo et al. 2012) classify them into two main categories according to the scope of the alignment: strategic alignment and operational, or process, alignment.

Strategic alignment is the degree to which a company's mission, goals, and business plans are shared and supported by IT strategy (Chan and Reich, 2007). According to Broadbent and Weill (Broadbent \& Weill, 1993), strategic business IT alignment represents the extent to which business strategies are enabled, supported, and stimulated by information strategies. Nadler and Tushman (Nadler and Tushman, 1983; Gerow, 2013) define business strategic alignment as the degree to which the IT department and business needs, demands, goals, objectives, and structures are consistent with each other. All definitions share a common vision of the alignment as the result of the consistency of several domains: strategy, organization, processes, ICT resources.

Operational alignment focuses on the functional side of the Information System, considering alignment as the fit between company's business processes and the functionalities provided by the System. In these process oriented studies, the application portfolio is considered $\mathrm{n}$ view of its support to business processes. 
Table 1. Classification of Models for Business IT Alignment ${ }^{1}$

\begin{tabular}{|l|l|}
\multicolumn{1}{|c|}{ Strategic Alignment } & \multicolumn{1}{c|}{ Operational Alignment } \\
\hline MIT90, Scott Morton (1991) & Tallon and Kraemer (1999) \\
Henderson and Venkatraman (1992) & Levy and Powell (2005) \\
Baets (1992) & Cragg et al. (2007) \\
Smaczny (2001) & \\
McDonad (1991) & \\
Ward and Peppard (2007) & \\
Maes (1999) & \\
Luftman (1996, 2007) & \\
\hline
\end{tabular}

\section{A Non-Exhaustive List of Models}

The MIT90 model, proposed at MIT by Scott Morton (Scott Morton, 1991) describes the alignment between strategy and ICT through the harmony of some key elements (Chan and Reich, 2007): strategy, structure, technology, individual roles, and management processes. The model also explores the relationship between internal factors and three external factors: society, economy, and external environment of science and technology development.

Developed on the MIT90 model, the Strategic Alignment Model (SAM) proposed by Henderson and Venkatraman (Henderson and Venkatraman, 1992) and based on the MIT90 investigates four key domains of alignment: business strategy, IT strategy, IS infrastructure and processes, organizational infrastructure and processes. The authors classify the domains into external (business strategy and IT strategy) and internal (IS infrastructure and processes, organizational infrastructure and processes), and in business (business strategy and organizational infrastructure and processes) and IT (IT strategy and IS infrastructure and processes) and analyses several alignment combinations. They conclude that strategic alignment is achieved when strategic and internal domains are aligned, while functional integration is achieved when there is fit between business and IT.

Despite the clear vision and the identification of the relevant alignment domains, some researchers argue that SAM is too broad and lacks the capability to provide practical tools to help managers take decisions (Avison et al., 2004), especially in companies where there is no structured decisional process or strategic process. Baets (Baets, 1992) recognized that in many organizations there is no explicit strategy formulation process, or it is not shared with all managers, and proposes to consider the alignment as a process involving four activities: business strategy, organizational infrastructure and process, Information Systems infrastructure and process, and ICT strategy.

Several researchers attempted to extend SAM in order to enhance the applicability to companies.

McDonald (McDonald, 1991) introduced the relationship of the organization with external actors, customers and suppliers into the model, and details the various cycles needed to obtain the alignment.

\footnotetext{
${ }^{1}$ Scientific and business literature on business IT alignment is extremely wide, therefore the list of models analysed in the paper is not exhaustive. Publications were selected in order to show main research trends in alignment and highlight gaps.
} 
Goedvolk et al. (Goedvolk et al., 1997) focused on technical and architectural requirements, moving towards an interpretation of the alignment more oriented to the design of the target ICT configuration.

Luftman (Luftman, 1996, 2007) tried to transform the model into a management tool through the introduction of governing alignment perspectives (the communication between business and technology management levels) and identifying enablers and inhibitors to alignment.

Maes (Maes, 1999; Maes et al. 2000) developed a unified framework that integrates additional functional layers that reflect the need for information and communication within the organization.

The thesis of the inapplicability of strategic approaches was supported by several authors who concluded that an alignment process approach proved to be more effective than a strategic one (Cataldo et al., 2012; Avison et al., 2004, Levy et al., 2007).

Cragg et all (Cragg et al., 2007) proposed a methodology to align IT infrastructure and processes based on a processes standard classification of processes (PCF, Process Classification Framework), defined by APQC (American Productivity and Quality Centre's International Benchmarking Clearinghouse, 2005). The authors introduced the notion of moderation to evaluate the alignment and then compared it with IT success. They proposed a significant correlation between process alignment and IT success.

Levy and Powell (Levy and Powell, 2005) proposed a model based on customer relationships and business focus (namely the "focus dominance"). Four types of business foci are considered: efficiency, coordination, partnership and repositioning. Companies were therefore classified according to the business focus and the number of customers. The authors then suggested how to seek alignment for each type of company highlighting the configuration that better provided efficiency and effectiveness.

\section{Considerations on Alignment Models}

The value of strategic approaches to alignment lays in the capability to identify and analyse all the relevant alignment domains. This broadens the vision of decision makers and unfolds the opportunity of using ICT to support and to innovate the way of doing business.

However, strategic approaches lack the capability to be transformed into operational tools, and only a limited number of companies that have structured strategic and IT decisional processes can apply them fruitfully (Cataldo et al., 2012; Avison et al., 2004; Cragg et al., 2007).

Operational approaches prove to be more practicable. They are based on a process view of organizations whose support by ICT is more suitable to be assessed, measured and improved. Furthermore they embed the idea of an iterative sequence of actions to achieve reach alignment, which is consistent with the natural evolution of companies and the environment they compete in, and the consequent necessity to continuously revise ICT choices. However there is a tendency to identify and indicate activities and methodologies to 
reach a certain degree of alignment, rather than proposing the target state of the Information System (Jarvenpaa and Ives, 1993; Thompson and Iacovou 1993).

In general, alignment models address in a limited way the need of flexibility to cope with environmental uncertainty and the consequent turbulence as a design parameter for the Information System. Environmental uncertainty, defined as the degree of change and instability in a company's operating context, has an impact on performances, according to Tallon and Pinsonneault (Tallon and Pinsonneault, 2011). In times of high environmental uncertainty, organizations have a stronger need for information and flexible Information Systems. Uncertainty may come from several origin. Volberda (Volberda, 1999) and Sopelana et al. (Sopelana et al., 2012) identify three main sources of turbulence in organizations: dynamism, which is related to the frequency and intensity of changes in competition; technology and other environmental factors, complexity, which is related to the number, variability, and interconnectedness of environmental factors that cause change; predictability, which depends on the availability of data, its clarity and managers' awareness of it. Even though these analyses originated in organizational studies, they can be applied to investigate the relationship between turbulence and ICT, as part of company's technology.

Under the flexibility perspective, process-oriented alignment models seem to better address the vision of companies as organizations which constantly adapt to changes and contingences coming from external environment and internal pressures. IT is seen as a set of resources to be deployed according to business needs that are deemed to change over time (Thompson and Iacovou, 1993).

\section{Framework for Alignment}

The proposed framework for business IT alignment intends to overcome, in several respects, some of the limitations of existing models.

The framework is the result of a quantitative and qualitative research that involved 48 case study analyses on Italian manufacturing SMEs over the period 2006 - 2010. Each company completed a structured questionnaire and an interview to collect data on several aspects: competitive position, organization structure, supply chain and sales network, quantitative data on turnover and employees, market trends, application portfolio and Information System architecture and their evolution in recent years, processes and performances, IT decision process and budget formulation. The backward application of the framework to data provided suggestions, which were presented to the interviewed to verify their quality. The framework was therefore tested and applied to 8 companies that were starting a process of renovation of their Information Systems. One of these case studies is discussed at the end of the paper.

The following design principles have been adopted in the framework definition: 
a) The framework focuses on process alignment, through the assessment of parameters that are easily collectable and measurable.

b) To overcome the inapplicability of existing models that analyse the whole company's Information System, the framework adopts a more granular approach (Farrel, 2003; Chan and Reich, 2007; Taskin and Varville, 2010) and centres on the application portfolio (Ward and Peppard, 2007).

c) The framework leverages on existing approaches, rather than proposing new ones, to collect business needs and proposes the company's target application portfolio. The approach aims at being straightforward, easily applicable by managers, who seek to identify the appropriate configuration of the application portfolio.

d) The framework clearly incorporates flexibility as a design parameter to define the target application portfolio (Sopelana et al., 2012, Taskin, 2010)..

The framework is based on the three steps of analysis and design:

- The assessment of business needs, actual and foresees, if possible.

- The assessment of the Information System Maturity, the capacity of Information System to support business needs and guarantee flexibility.

- The gap analysis and the suggestion of the target application portfolio configuration.

\section{Identification of Business Needs}

The approach to identify business needs is based on some assumptions on the role of the Information System. Company's Information System should: (i) automate information-based processes and enhance management efficiency, by providing completed and integrated information for decisional purposes (Hirschheim and Klein, 1989); (ii) improve competitive advantage through the opportunity to reorganize and renovate the way of doing business (Taskin, 2010; Ward and Peppard, 2007); (iii) provide adaptability properties to support new business needs caused by changes in internal processes and face external pressures (Duncan 1995; Kamoun, 2013).

Business needs associated with automation, and decision support can be formalized through the notion of company's complexity, namely product, process, and organizational complexity (Table 2). This formulation of complexity extends the information intensity matrix originally proposed by Porter and Miller (Porter and Miller, 1985), introducing the role of the organization, in terms of needs, to support interoperability among different partners in the networked enterprise.

A product or service is complex according to the quantity and heterogeneity of information necessary to describe and manage it during its lifecycle, from design to post-sale, in a company. Drivers of product 
complexity comprise: number and variability of finished product, bill of material, number of technologies embedded in the product, number rules and constraints related to the combination of components within the product. The need of more sophisticated applications to manage complex products is related not only to the necessity to store higher volumes of data, but mostly to the need of elaborating, transforming, sharing complex data with among actors.

Process complexity is related to the number and intricacy of phases necessary to realize products. Drivers of process complexity are: number of processes managed, number of phases, heterogeneity of phases, number of workers involved in each phase, combination of different process management strategies. The higher the process complexity, the more mature the application portfolio should be in terms of completeness of functionalities and capacity to support different processes.

Organization complexity reflects the interconnection of actors, business units and companies involved in business activities. Drivers of organization complexity comprise: number of business units and plans, number of target markets, suppliers, third parties, and number of clients, heterogeneity of the actors in terms of technology evolution, nationalities, capacity to manage information, structure of supply chain. Complex organizations need an application portfolio capable of adapting to different interfaces, supporting diverse communication channels and heterogeneous data exchange formats.

Table 2. Complexity Indicators

\begin{tabular}{|c|c|}
\hline Complexity types & Drivers \\
\hline Product complexity & $\begin{array}{l}\text { - Number and variability of finished product } \\
\text { - Complexity of the Bill of Material } \\
\text { - Number of technologies embedded in the product } \\
\text { - Number of rules and constraints related to the } \\
\text { combination of components within the product }\end{array}$ \\
\hline Process complexity & $\begin{array}{l}\text { - Number of phases } \\
\text { - Number of actors involved in the phases } \\
\text { - Heterogeneity of phases } \\
\text { - Combination of different process management } \\
\text { strategies }\end{array}$ \\
\hline Organization complexity & 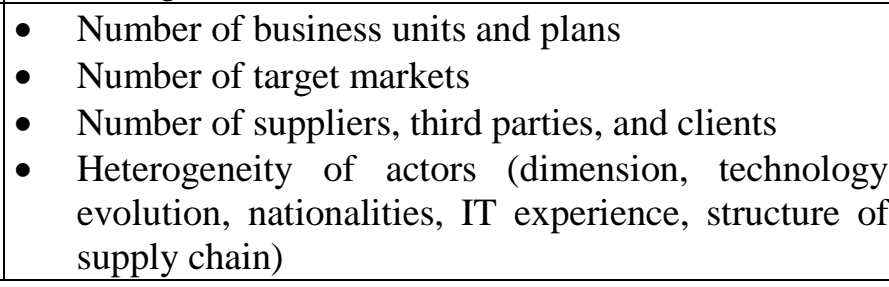 \\
\hline
\end{tabular}

The business need associated with the company's requirement of flexibility can be evaluated through the notion of uncertainty, which may arise both from inside the company as well as being an external environment condition. All dimensions of complexity can be affected by uncertainty. The following indicators are identified and assessed exploiting Volberda's analysis on the sources of uncertainty, (Table 3): 
- Variability, which derives from the frequency and intensity of corporate changes (product, process, organization) and of changes in competitive environment (e.g. variability of competitive position, variability of sales).

- Intricacy, which derives from the number, and interconnectedness between company's business and factors that cause change (product or process dependence on technology, competition in regulated markets such as Food and Beverage, Pharmaceutical Intricacy).

- Knowledge, awareness and quality of data, which derive from the availability and clarity of data to make affordable predictions and take effective decisions.

Variability and intricacy increase uncertainty, while knowledge, awareness and quality of data improve company's capacity to cope with uncertainty.

Table 3. Uncertainty Indicators

\begin{tabular}{|l|l|}
\hline Uncertainty indicators & \multicolumn{1}{|c|}{ Drivers } \\
\hline Variability & $\begin{array}{l}\text { Frequency of corporate changes in organization } \\
\text { (product, process, organization) } \\
\text { Frequency of changes in competitive environment } \\
\text { Intensity of internal changes } \\
\text { Intensity of environment changes }\end{array}$ \\
\hline Intricacy & $\begin{array}{l}\text { Number of causes of change } \\
\text { Dependency on un-controllable causes of change (e.g. } \\
\text { technology, regulation) }\end{array}$ \\
\hline $\begin{array}{l}\text { Knowledge, awareness and } \\
\text { quality of data }\end{array}$ & $\begin{array}{l}\text { Historical datasets } \\
\text { Market forecasts } \\
\text { Capacity to influence and determine intricacy } \\
\text { parameters }\end{array}$ \\
\hline
\end{tabular}

\section{Information System Maturity Model}

The evolution of the company's Information System in terms of its capability to match business needs and readiness to evolve in a flexible way can be measured using two dimensions:

- Efficacy, which measures the integrated support provided by the application portfolio to business processes in an integrated way. The higher the number of processes supported by applications and their integration, the higher the efficacy of the Information System. Several strategies can be obtained to enhance efficacy, such as the introduction of applications dedicated to specific processes, customization and development of applications, development of connectors among applications, introduction of middleware or enterprise service buses, development of connectors, database integration or use of database integration functionalities (e.g. ETL, Extraction, Transaction and Loading). 
- Flexibility, which is related to agility, to the capacity to reorganize ICT resources to achieve adaptation to new business needs, and to speed, measure the ability of the ICT resources to expeditiously implement adjustments (Power and Reid, 2005). Technological properties that affect agility and speed include the native functional coverage of the applications, modularity, connectivity and openness of application (in terms of access to source code and tables in databases), compatibility (in terms of adoption of standard interfaces), and novelty or maturity.

According to the two dimensions, several configurations of the application portfolio exist (Figure 1).

Figure 1. Information System Maturity Model

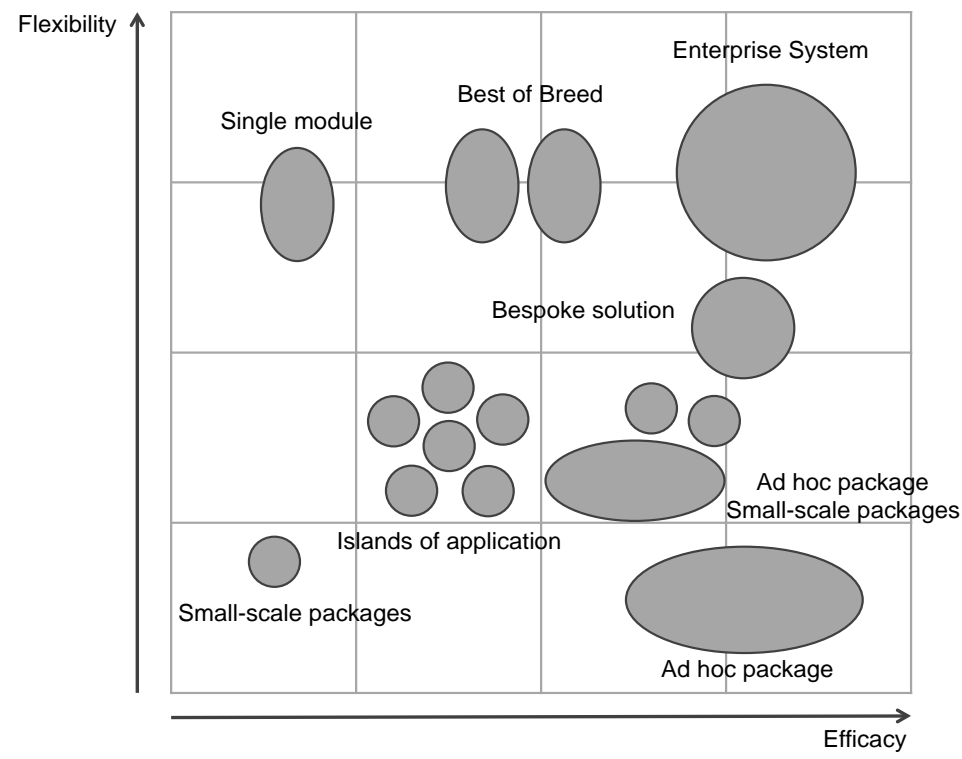

Small-scale packages. They are characterized by simplicity, support basic needs or processes of departments or business units (e.g. administrative functionalities which are localized in each country), and are often developed by small software companies.

"Islands of applications" (Lam, 2007). The company can enhance the coverage of its needs through the adoption of several small-scale packages integrating them at different degrees. The degree of integration influences the efficacy of the application portfolio, while the technology adopted for integration affects the flexibility of the portfolio.

Ad hoc developed packages. They can be developed in-house or realized by software companies on the basis of detailed requirements of the company. They perfectly fit the needs of the company. They are often characterized by proprietary technology and limited scalability.

Enterprise Systems. They are large-scale packages (such as ERP, CRM, SCM), organized into modules and potentially capable of supporting a wide range of business needs. From a technological perspective they are 
characterized by a single database, based on up-to-date developing languages, adoption of standards. They often provide interfaces or middleware to support integration with other packages. From a business perspective, they are generally business neutral and general purpose, and implementation in companies requires analysis and customization. The higher the customization, the lower the flexibility of the package. Functionalities and peculiarities for specific industries have been collected into bespoke modules (or vertical modules).

Bespoke solutions. They are packages tailor made to the needs of individual businesses or departments. Despite ad hoc packages, they are usually based on standard and updated technologies, guaranteeing compatibility with other packages and higher flexibility.

Several combinations of the previous solutions can be implemented by companies, combining small-scale packages with ad hoc systems or bespoke solutions, enterprise systems with bespoke modules, or choosing and integrating modules from different enterprise system providers (attitude usually named Best of Breed approach) to determine a final application portfolio.

\section{Considerations on Alignment}

The assessment of business and flexibility needs lead to the identification of the requirements of the desired Information Systems. The Information System Maturity Model provides information on the capability of the Information System to match the requirements.

The comparison of the two indications provides information on business IT alignment as well as suggestions on how to fill gaps, if they exist.

Figure 2. Measure of Business and Flexibility Needs (left) and of IS Maturity (Right).
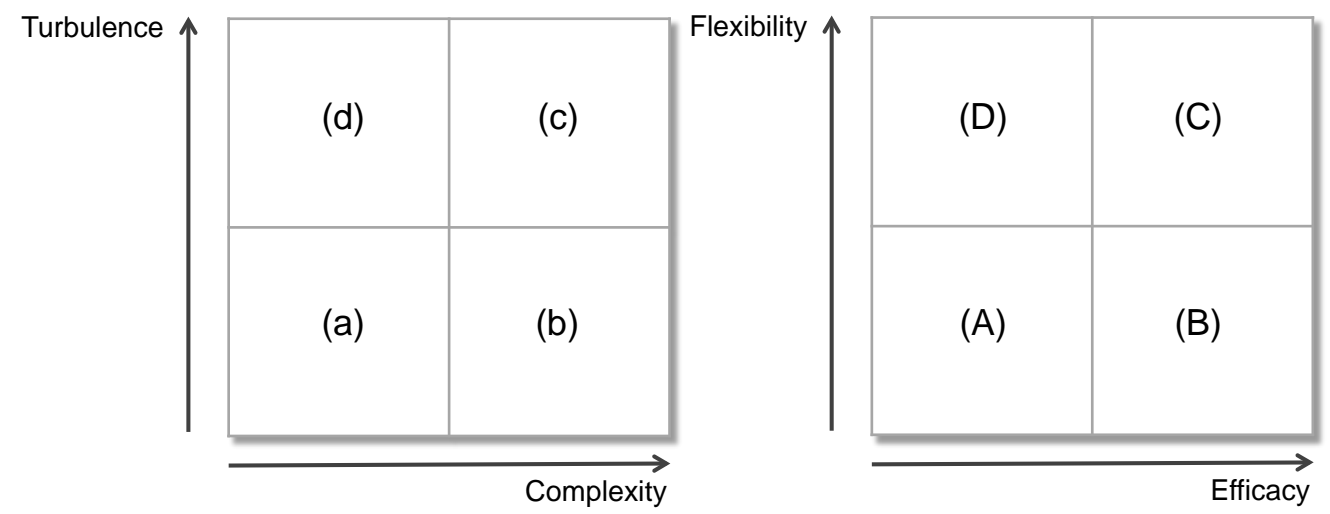

Among the configurations of alignment, it is to be noted that:

- (a)-(A) represents the case of simple companies, where applications have a marginal role. 
- (d)-(D) is usually the case of small companies, where the evolution process of the Information System is not complete yet, because recently established (e.g. start-ups) or due to a transformation process;

- (b)-(B) represents a legacy configuration, where the Information System is the result of a process of evolution which lead to a system tailor made and providing all specific functionalities needed by the company. This configuration can be considered an "alignment-trap" (Shpilberg et al., 2007), as sudden changes or unexpected events may threaten the company's survival;

- (c)-(C) is the configuration of mature companies, IT-enabled, where IT perfectly matches current needs but is also capable of supporting future evolution.

Due to the natural path of evolution of the application portfolio which is characterized by a tendency to add and integrate new applications to support new business needs, endowing the efficacy of the application portfolio rather than its flexibility), horizontal misalignment, (a)-(B) or (d)-(C), is quite rare or represents a temporary condition during the process of evolution.

Among the misaligned configurations, it is to be noted that:

- (b)-(A) is easily recoverable, as in conditions of basic application portfolio its replacement has a limitedly impact on the company;

- (c)-(B) represents a critical and risky condition, where the company's application portfolio is not capable of satisfying the complexity and turbulent competitive environment. Alignment can be pursued only at the cost of a temporary, and expensive, horizontal misalignment.

\section{Case Study}

Baltur S.p.A. is an Italian family-run business that produces heating, burners and modular boilers, and markets cooling devices..

The company was established in 1950. In 2011, after 60 years, a transfer of property, and a turnover of around 42 million Euro, the company was facing an uncertain competitive environment. The local (Italian) market, which accounted for $60 \%$ of corporate sales, was suffering purchases reduction due to the national demand shrinkage, while foreign markets looked promising but dynamic. The company had one main production plant for heating systems in the north of Italy, while it was importing and selling cooling devices. It could leverage on subcontractors for production of specific components. The company served the Italian market through a network of professionals and small shops (around 900 in total), and at international level it had agreements with importers and exporters in around 40 countries. 
The application portfolio was the result of a long process of adjustments to business needs, as well as the fruit of choices of different CEOs and managers.

It was composed of several packages: one package strongly customized which supported all main internal processes (administration, production management, warehouse, account payable, account receivable); a number of packages dedicated to specific processes (e.g. logistics, production control, reporting and Business Intelligence, design and PDM, quality tests, Web orders entry). The packages were partially integrated using heterogeneous technologies.

The application portfolio was reaching the limit and the framework for alignment was applied to identify gaps and define the target configuration of the Information System (Figure 3, Figure 4).

Figure 3. Company's Assessment of Business Needs

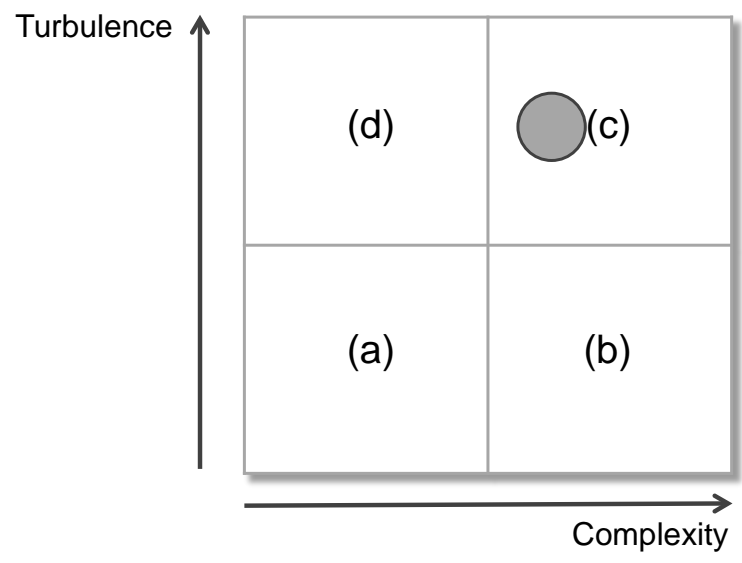

Figure 4. Company's Information System Maturity

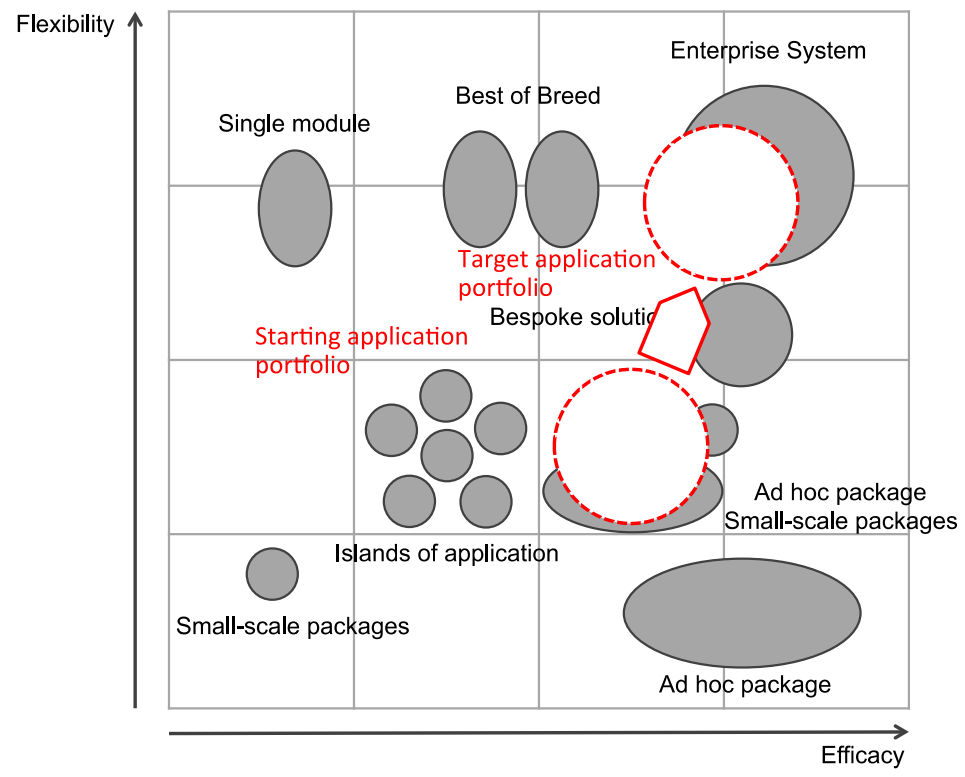


After the assessment, an Enterprise System configuration of the application portfolio based on a market-leader ERP package was chosen. Only a small number of packages (which were strongly customized or not critical for the business) were left and were integrated with the ERP. The ERP project was completed in one year in December 2012, with "go-live" phase in January 2013.

During 2013 the company faced some unexpected and relevant changes: considerable sales growth in foreign markets, previously limitedly served, which impacted the product lines and brought the necessity to re-organize the sales structure, replacement of the CAD system with a PDM solution, creation of a completely new post-sales service department.

The Information System supported all changes without evident limitations or hindering company's business performances.

\section{Conclusions and Future Research}

Company's business IT alignment is the result of a process of harmonization of several domains: corporate strategy, IT strategy, processes, and organizational infrastructure. Models and approaches described in literature mainly focus on the analysis of the alignment from a strategic perspective. Several authors argue that the models proposed don't possess the required characteristics for application to companies' decision processes. Some arguments include: broad definition of Information System, lack of measurable indicators to guide the alignment, focus on the methodology rather than on the target Information System configuration.

Furthermore, literature analyses the relationship between uncertainty and company's performance, but flexibility requirements for the Information System have not been yet considered as a design parameter.

The research papers analyses business IT alignment from the operational and target oriented perspective taking into consideration the role of flexibility in the Information System design.

The framework proposed in the paper encompasses two dimensions of analysis: business and flexibility needs and maturity of the Information System.

The framework proves to be a useful and operational instrument that can guide companies in ICT choices and was successfully applied to 10 case studies.

However, the framework captures only some facets of the alignment problem and ignores aspects which could drive the need of ICT, such as ICT 'culture' or ICT 'skills", the role of ICT in the business (ancillary, operational, key) in the business and in the product or service of the company. These aspects represent the base for future research. 


\section{References}

Avison, D., Jones, J., Powell, P., \& Wilson, D. (2004). Using and validating the strategic alignment model. The Journal of Strategic Information Systems, 13(3), 223-246.

Baets, W. (1992). Aligning information systems with business strategy. The Journal of Strategic Information Systems, 1(4), 205-213.

Broadbent, M., Weill, P. (1993). Improving business and information strategy alignment: learning from the banking industry. IBM Systems Journal, 32(1), 162179.

Cataldo, A., McQueen, R. J., \& Hardings, J. (2012). Comparing Strategic IT Alignment versus Process IT Alignment in SMEs. Journal of Research \& Practice in Information Technology, 44(1).

Chan, Y. E., \& Reich, B. H. (2007). IT alignment: what have we learned?.Journal of Information technology, 22(4), 297-315.

Chan, Y.E., Huff, S.L., Barclay, D.W. and Copeland, D.G. (1997). Business Strategic Orientation, Information Systems Strategic Orientation, and Strategic Alignment, Information Systems Research 8(2): 125-150.

Choe, J. M. (2003). The effect of environmental uncertainty and strategic applications of IS on a firm's performance. Information \& Management, 40(4), 257-268.

Chung, S. H., Rainer Jr, R. K., \& Lewis, B. R. (2003). The Impact of Information Technology Infrastructure Flexibility on Strategic Alignment and Applications Implementation. Communications of the Association for Information Systems, 11.

Cragg, P. B., \& Tagliavini, M. (2006). Evaluating information systems alignment in small firms. Department of Accountancy, Finance and Information Systems, University of Canterbury.

Cragg, P., Tagliavini, M., \& Mills, A. (2007). Evaluating the alignment of IT with business processes in SMEs.

Duncan, N. B. (1995). Capturing flexibility of information technology infrastructure: A study of resource characteristics and their measure. Journal of Management Information Systems, 12(2), 37-57.

Farrell, I.J. (2003). Aligning IT to Corporate Objectives: Organisational factors in use, Unpublished Doctoral Dissertation, Macquarie University, Sydney.

Gerow, J. (2013). Research-in-Progress: Understanding the Relationship between ITBusiness Strategic Alignment and Firm Performance.

Goedvolk, H., Van Schijndel, A., Van Swede, V., \& Tolido, R. (2000). The design, development and deployment of ICT systems in the 21st century: integrated architecture framework (IAF). Cap Gemini Ernst and Young. http:// home.hetnet.nl/ daanrijsenbrij/ progx/eng/contents.htm: Cap Gemini Ernst and Young.

Henderson, J. C., \& Venkatraman, N. (1992). Strategic alignment: a model for organizational transformation through information technology (pp. 97-116). Oxford University Press, New York.

Hirschheim, R., \& Klein, H. K. (1989). Four paradigms of information systems development. Communications of the ACM, 32(10), 1199-1216.

Jarvenpaa, S. L., \& Ives, B. (1994). The global network organization of the future: Information management opportunities and challenges. Journal of management information systems, 10(4), 25-57.

Jarvenpaa, S. L., \& Ives, B. (1993). Organizing for Global Competition. Decision Sciences, 24(3), 547-580. 
Kamoun, F. (2013). Rethinking the Role of Enterprise Architecture During Times of Economic Downturn: A Dynamic Capabilities Approach. Journal of Information Technology Management, 24(1), 26.

Knoll, K., \& Jarvenpaa, S. L. (1994, April). Information technology alignment or "fit" in highly turbulent environments: the concept of flexibility. In Proceedings of the 1994 computer personnel research conference on Reinventing IS: managing information technology in changing organizations: managing information technology in changing organizations (pp. 1-14). ACM.

Lam, W. (2007). Information Systems Integration and Enterprise Application Integration (EAI) Adoption: A Case from Financial Services. Journal of Information Systems Education, 18(2).

Levy, M., \& Powell, P. (2004). Strategies for Growth in SMEs: The Role of Information and Information Sytems. Butterworth-Heinemann.

Levy, M., Powell, P., \& Yetton, P. (2001). SMEs: aligning IS and the strategic context. Journal of Information Technology, 16(3), 133-144.

Levy, M., \& Powell, P. (1998). SME flexibility and the role of information systems. Small Business Economics, 11(2), 183-196.

Luftman, J., Kempaiah, R. and Nash, E. (2005). Key Issues for IT Executives 2005, MIS Quarterly Executive 5(2): 81-101.

Luftman, J. N. (Ed.). (1996). Competing in the information age: strategic alignment in practice. Oxford University Press.

Luftman, J., \& Kempaiah, R. (2007). An Update on Business-IT Alignment:" A Line" Has Been Drawn. MIS Quarterly Executive, 6(3).

Maes, R. (1999). A Generic Framework for Information Management, Prime vera Working Paper, Unpublished manuscript.

Maes, R., Rijsenbrij, D., Truijens, O. and Goedvolk, H. (2000). Redefining Business-IT Alignment through A Unified Framework, Universiteit van Amsterdam/Cap gemini White Paper, Unpublished manuscript.

MacDonald, H. (1991). The strategic alignment process. The Corporation of the 1990s: Information Technology and Organisational Transformation.

Nadler, D., and Tushman, M. "A general diagnostic model for organizational behavior: Applying a congruence perspective," in: Perspectives on behavior in organizations, J.R. Hackman, E.E. Lawler and L.W. Porter (eds.), McGraw-Hill, New York, 1983, pp. 112-124

Orlikowski, W. J. (1996). Improvising organizational transformation over time: A situated change perspective. Information systems research, 7(1), 63-92.

Porter, M. E., \& Millar, V. E. (1985). How information gives you competitive advantage.

Power, B., \& Reid, G. C. (2005). Flexibility, firm-specific turbulence and the performance of the long-lived small firm. Review of Industrial Organization, 26(4), 415-443.

Prahalad, C. K., Thomas, H., \& O’Neal, D. (1998). Strategic flexibility. G. Hamel (Ed.). Wiley.

Scott Morton, M.S. (1991). The Corporation of the 1990s: Information technology and organizational transformation, London: Oxford Press.

Sabherwal, R., Hirschheim, R., \& Goles, T. (2001). The dynamics of alignment: Insights from a punctuated equilibrium model. Organization Science, 12(2), 179197.

Shpilberg, D., Berez, S., Puryear, R., \& Shah, S. (2007). Avoiding the alignment trap in information technology. MIT Sloan Management Review, 49(1), 51-58. 
Silvius, A. G., De Waal, B. M., \& Smit, J. (2009, July). Business and IT Alignment; Answers and Remaining Questions. In PACIS (p. 44).

Smaczny, T. (2001). Is an alignment between business and information technology the appropriate paradigm to manage IT in today's organisations? Management Decision, 39(10), 797-802.

Sopelana, A., Kunc, M., \& Hernáez, O. R. (2012). Towards a dynamic model of organisational flexibility. Systemic Practice and Action Research, 1-19.

Tallon, P. P., \& Pinsonneault, A. (2011). Competing Perspectives on the Link Between Strategic Information Technology Alignment and Organizational Agility: Insights from a Mediation Model. MIS Quarterly, 35(2).

Tallon, Paul, and Kenneth L. Kraemer (1999). A process-oriented assessment of the alignment of information systems and business strategy: implications for IT business value. Center for Research on Information Technology and Organizations (1999).

Taskin, N., \& Verville, J. (2010, June). An exploratory study on strategic alignment of enterprise systems and business strategies, performance, and flexibility. In Proceedings of 7th International Conference on Enterprise Systems, Accounting and Logistics (7th ICESAL 2010) (pp. 28-29).

Thompson, R. L., \& Iacovou, C. L. (1993). Information technology, critical success factors and organizational performance of small firms: a causal modelling approach. School of Business Administration, University of Vermont, Burlington, VT, Working Paper WP-MIS-93-006-1.

Turner, D. and Lankford, W. (2005). Information Technology Infrastructure: a Historical Perspective of Flexibility. Journal of Information Technology Management, Volume XVI, Number 2.

Vitale, M.R., Ives, B. and Beath, C.M. (1986). Linking information technology and corporate strategy: An organizational view, Proceedings of the Seventh International Conference on Information Systems, San Diego, USA. 265-276

Volberda, H. W. (1997). Building flexible organizations for fast-moving markets. Long Range Planning, 30(2), 169-148.

Volberda, H. W. (1999). Building the flexible firm: How to remain competitive. Oxford University Press.

Ward, J., \& Peppard, J. (2007). Strategic planning for information systems (Vol. 28). John Wiley \& Sons. 